\title{
Prevalence of primary dysmenorrhoea and its effect on instrumental activities of daily living among females from Pakistan
}

\author{
DOI: https://doi.org/10.5114/pq.2021.105754
}

Rabia Adil, Urfah Zaigham

University Institute of Physical Therapy, Faculty of Allied Health Sciences, University of Lahore, Gujrat Campus, Pakistan

\section{Abstract}

Introduction. Painful periods is one of the utmost general gynaecological disorders of adolescence. Therefore, the main aim of the study was to identify the prevalence of primary dysmenorrhoea and its effect on instrumental activities of daily living among females from Pakistan.

Methods. An observational cross-sectional study with a sample of 161 females was organized at University of Lahore, Gujrat Campus, Pakistan, between October 2019 and March 2020. The participants' age ranged between 18 and 36 years. Their body mass index was calculated through weight and height. The data were collected by using WaLIDD score (working ability, location, intensity, days of pain, dysmenorrhoea), visual analogue scale, and Lawton Instrumental Activities of Daily Living scale. Pearson correlation coefficient was used to evaluate the correlation between different variables. The data were analysed with the SPSS statistical software, version 20.0.

Results. Out of the 161 participants, $60.87 \%$ had moderate dysmenorrhoea, while mild and severe dysmenorrhoea was reported in $7.45 \%$ and $31.68 \%$, respectively. Most females (62.11\%) exhibited instrumental activities of daily living disability, while $37.89 \%$ had no disability. The results revealed that there were statistically significant associations between dysmenorrhoea and instrumental activities of daily living $(p=0.003)$. Significance was assumed at $p<0.05$.

Conclusions. Dysmenorrhoea had a statistically significant effect on instrumental activities of daily living $(p=0.003)$.

Key words: dysmenorrhoea, primary dysmenorrhoea, instrumental activities of daily living, WaLIDD score, Instrumental Activities of Daily Living scale, visual analogue scale

\section{Introduction}

Menstruation is a typical corporeal phenomenon occurring once each month in females of procreative age in association with impairment of the mucous membrane lining the uterus. The procedure is initiated with the collapse in the level of progesterone and oestrogen in the late stage of the menstruation cycle in the omission of gestation. Females may complain that they experience tenderness and pain in their low abdominal region before or during menstruation. Some women feel aching which is intensive enough to limit their normal everyday activities and demands medicament aid. This distress is described as dysmenorrhoea [1]. The term 'dysmenorrhoea' has Hellenic origin: 'dys' stands for 'arduous, aching, harrowing,' 'meno' refers to 'month,' and 'rhoea' means 'flow' [2].

Dysmenorrhoea is categorized in 2 groups. Primary dysmenorrhoea is defined as pain without apparent pathological pelvic infections or menstrual cycle disorders, with normal anatomy of the pelvic girdle; it usually initiates during pubescence, when the ovulation cycle is already well-organized. Secondary dysmenorrhoea is characterized as pain associated with a gynaecological pathology; it normally occurs some years after the menarche and is more prevalent in women aged $>20$ years [3, 4].

Indications of pain may arise several days prior to menstruation and last for a variable number of days [5]. In dysmenorrhoea, pain is usually located in the lower limbs and the low-back region [6]. Dysmenorrhoea may also be related with other symptoms, comprising headache, diarrhoea, vomiting, and biliary tract disorders. These may occur prior to menstruation or with the periods [7]. Sometimes, menstrual pain coexists with lower back ache, lethargy, giddiness, and fainting $[8,9]$.

There are several risk factors for dysmenorrhoea. They include history of menstrual pain in the family, overweight $[10,11]$, early menarche, low body mass index (BMI), adolescence [12], smoking, and prolonged and hefty menstruations [13]. The predictors of dysmenorrhoea involve irregular menstrual cycles, skipping breakfast, academic specialization (medical specialization as compared with studying the humanities), high stress level, and living in a dormitory [14]. In some women, dysmenorrhoea may be related with mood disorders, sleep disturbances, and limitations in the performance of daily life routines such as education and work [15].

It was reported that dysmenorrhoea might affect $>80 \%$ of females in their fertile age [16]. Primary dysmenorrhoea is highly prevalent in teenagers as compared with older women as it may relieve with age. The frequency of menstrual pain in Pakistan was revealed to be $56.1 \%$ among medical students in Mirpur, Azad Kashmir [17]. Dysmenorrhoea occurs less often in married females $(43 \%)$ than in unmarried women $(57 \%)$ [18].

Dysmenorrhoea exerts detrimental effects on the private life of young adults as it is bound with their social and educational performance. Dysmenorrhoea and distress causes disability (impairment in tasks and activities) and handicap (change in the social functions) [19]. The management of menstrual pain depends on its form; in secondary dysmenorrhoea, treatment is targeted at curing the underlying pa-

Correspondence address: Urfah Zaigham, University Institute of Physical Therapy, Faculty of Allied Health Sciences, University of Lahore, Campus in Gujrat, Adjacent Chenab Bridge, Gujrat, Punjab, Pakistan-52000, e-mail: urfah.zaigham@uipt.uol.edu.pk 
thology. Nevertheless, in primary dysmenorrhoea, such procedures are applied as hot bags, well-balanced nutrition, daily exercise, regular and adequate sleep, massage, or drug treatment. Stylostixis, shiatsu, spinal column manipulation treatment, yoga, vitamin and mineral supplementation, and vegetative therapies are among the means of holistic treatment [20].

The capability to accomplish the instrumental activities of daily living predicts important health consequences. These activities are significant in rehabilitation and health care, since they constitute the tasks that individuals must be capable to achieve or have achieved for them if they are to live safely and soundly in the society [21]. Instrumental activities of daily living are essential for functioning and depend on cognitive and physical impairments. These dependencies reflect high order functional impairments owing to the cognitive commands necessary for successful task fulfilment. Furthermore, they are related to an extensive range of cognitive impairments, and new instrumental activity dependency predicts a future decline in cognitive function [22].

The aim of the research was to assess the prevalence of primary dysmenorrhoea and its effect on instrumental activities of daily living among females at the University of Lahore, Gujrat Campus, in Pakistan; the results would make a valuable contribution to the literature.

The hypotheses put forward in the present study were as follows:

- Null hypothesis $\left(\mathrm{H}_{0}\right)$ : Dysmenorrhoea has no significant effect on instrumental activities of daily living.

- Alternate hypothesis $\left(\mathrm{H}_{1}\right)$ : Dysmenorrhoea has a significant effect on instrumental activities of daily living.

\section{Subjects and methods}

\section{Participants and design}

An observational cross-sectional study with a sample consisting of 161 females [23] was organized at the University of Lahore, Gujrat Campus. The participants were selected with the method of non-probability convenience sampling, with the subsequent selection benchmarks. Included were unmarried females [23] aged 18-36 years, having regular menstrual cycles [12, 24]. Exclusion criteria involved acute or chronic pelvis diseases, irregular menstruation, secondary dysmenorrhoea, self-delineated manifestations, i.e. vaginal itchiness, agonizing, or unusual excretions, and history of gynaecologic operations.

A structured questionnaire was used to assemble the sociodemographic data. Weight $(\mathrm{kg})$ and height $(\mathrm{m})$ were measured and then BMI $\left(\mathrm{kg} / \mathrm{m}^{2}\right)$ was calculated. WaLIDD score (working ability, location, intensity, days of pain, dysmenorrhoea) was determined to depict the presence and intensity of dysmenorrhoea. The participants were requested to encircle the 4 divisions of the WaLIDD score. To assess the total level of dysmenorrhoea, the score of each division was counted. Each variable gives a score of $0-3$, and the total score ranges $0-12$ points. The total score of 0 implies no dysmenorrhoea, $1-4$ represents a mild, 5-7 a moderate, and 8-12 a severe form of dysmenorrhoea. To find out the pain intensity, the visual analogue scale (VAS) was applied. The females were asked to encircle their related pain section. VAS is normally ranged from 0 on the left, meaning 'least extreme,' to 10 on the right, indicating 'most extreme'. The total score of 0 stands for no pain, 1-3 shows mild, 4-6 moderate, 7-9 severe, and 10 the worst pain. The Lawton Instrumental Activities of Daily Living (IADL) scale served to identify the impact of dysmenorrhoea on instrumental activities of daily living. It consists of 8 categories. The subjects were asked to circle an answer to each category. 'Yes' stood for 'able to do' and represented 1 point, and 'no' meant 'unable to do' and represented 0 points. The final score was obtained by adding all the scores of each participant. Females having the final score of $\leq 4$ were confirmed as having instrumental activities of daily living disability.

Participants with diagnosed primary dysmenorrhoea were selected through WaLIDD score and their pain intensity was assessed with VAS. Then, the Lawton IADL scale was applied to identify the effect of dysmenorrhoea on instrumental activities of daily living.

\section{Data analysis procedure}

In descriptive analysis, for quantitative variables (e.g. age, BMI, WaLIDD score, VAS, and IADL scale of the participants), mean and standard deviation was calculated. For qualitative variables (e.g. age, occupation, and BMI of the participants), the frequency $(n)$ and percentages (\%) were determined. These were also established for dysmenorrhoea WaLIDD score, VAS for pain intensity, and Lawton IADL scale. The Pearson correlation coefficient $(r)$ was used to measure the correlations between dysmenorrhoea and instrumental activities of daily living. The data were analysed with the SPSS statistical software, version of 20.0. Results were considered significant at $p<0.05$.

\section{Ethical approval}

The research related to human use has complied with all the relevant national regulations and institutional policies, has followed the tenets of the Declaration of Helsinki, and has been approved by the Research Ethics Committee of the University Institute of Physical Therapy at the University of Lahore, Gujrat Campus, Punjab, Pakistan.

\section{Informed consent}

Informed consent has been obtained from all individuals included in this study.

\section{Results}

Out of the 161 participants, 131 (81.40\%) were aged 18-23 years, 29 (18.00\%) were aged $24-29$ years, and 1 $(0.60 \%)$ was aged $30-36$ years. With reference to occupation, 141 women $(87.60 \%)$ were students, 16 (9.90\%) were the faculty members, and $4(2.50 \%)$ were the staff management. The participants' BMI showed that $32(19.90 \%)$ were underweight, 107 (66.50\%) were normal weight, 15 (9.30\%) were overweight, and 7 (4.30\%) were obese.

Means and standard deviations of age, BMI, WaLIDD score, VAS, and IADL scale of the participants are presented in Table 1.

Table 1. Characteristics of study participants

\begin{tabular}{|l|c|}
\hline Variables & Mean $\pm S D$ \\
\hline Age $($ years $)$ & $21.71 \pm 2.64$ \\
\hline BMI $\left(\mathrm{kg} / \mathrm{m}^{2}\right)$ & $21.47 \pm 4.29$ \\
\hline WaLIDD score & $6.76 \pm 1.65$ \\
\hline VAS score & $5.99 \pm 1.96$ \\
\hline IADL score & $3.93 \pm 1.96$ \\
\hline
\end{tabular}

BMI - body mass index, WaLIDD - working ability, location, intensity, days of pain, dysmenorrhoea, VAS - visual analogue scale, IADL - Instrumental Activities of Daily Living scale 
The percentage distribution of the participants in accordance with the WaLIDD score for dysmenorrhoea is elaborated in Table 2.

Figure 1 shows the percentage distribution of dysmenorrhoea severity.

When the intensity of pain during dysmenorrhoea was evaluated with VAS, $42.90 \%$ of females had severe pain, $41.00 \%$ had moderate pain, $15.50 \%$ had mild pain, and $0.60 \%$ had worst pain. The division of pain intensity percentages in accordance with VAS among the participants is summarized in Table 3.

The effect of dysmenorrhoea on the instrumental activities of daily living was evaluated by the Lawton IADL scale, which revealed that more than half of the participants $(62.11 \%)$ exhibited instrumental activities of daily living disability and $37.89 \%$ had no disability, as illustrated in Figure 2.

Table 2. Characteristics and percentage distribution of WaLIDD score

\begin{tabular}{|c|c|c|}
\hline \multicolumn{2}{|c|}{ WaLIDD score elements } & $n(\%)$ \\
\hline \multirow{4}{*}{ Working ability } & 'None' & $16(9.90 \%)$ \\
\hline & 'Almost never' & $57(35.40 \%)$ \\
\hline & 'Almost always' & $63(39.10 \%)$ \\
\hline & 'Always' & $25(15.50 \%)$ \\
\hline \multirow{3}{*}{ Location } & '1 site' & $50(31.10 \%)$ \\
\hline & '2-3 sites' & $101(62.70 \%)$ \\
\hline & '4 sites' & $10(6.20 \%)$ \\
\hline \multirow{3}{*}{ Wong-Baker intensity } & 'Hurts a little' & $31(19.30 \%)$ \\
\hline & $\begin{array}{l}\text { 'Hurts a little more } \\
\text { or hurts even more' }\end{array}$ & $88(54.70 \%)$ \\
\hline & $\begin{array}{l}\text { 'Hurts whole lot } \\
\text { or hurts worst' }\end{array}$ & $42(26.10 \%)$ \\
\hline \multirow{3}{*}{ Pain duration (days) } & '1-2' & $113(70.20 \%)$ \\
\hline & '3-4' & $41(25.50 \%)$ \\
\hline & $\geq 5$ ' & $7(4.30 \%)$ \\
\hline
\end{tabular}

WaLIDD - working ability, location, intensity, days of pain, dysmenorrhoea

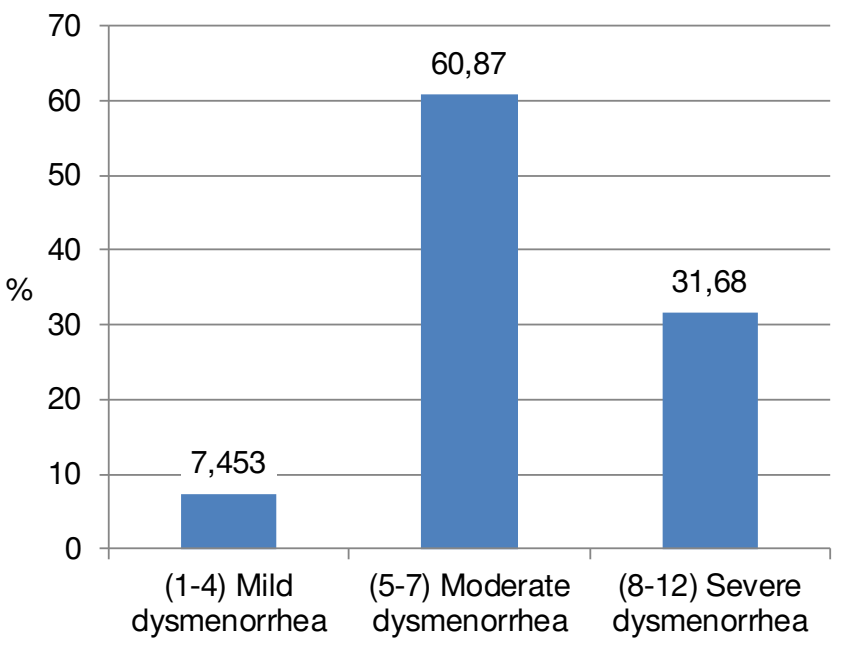

WaLIDD Score
Table 3. Pain intensity percentages among the participants in accordance with visual analogue scale

\begin{tabular}{|l|c|}
\hline Visual analogue scale categories & $n(\%)$ \\
\hline 1-3: 'mild pain' & $25(15.50 \%)$ \\
\hline 4-6: 'moderate pain' & $66(41.00 \%)$ \\
\hline 7-9: 'severe pain' & $69(42.90 \%)$ \\
\hline 10: 'worst pain' & $1(0.60 \%)$ \\
\hline
\end{tabular}

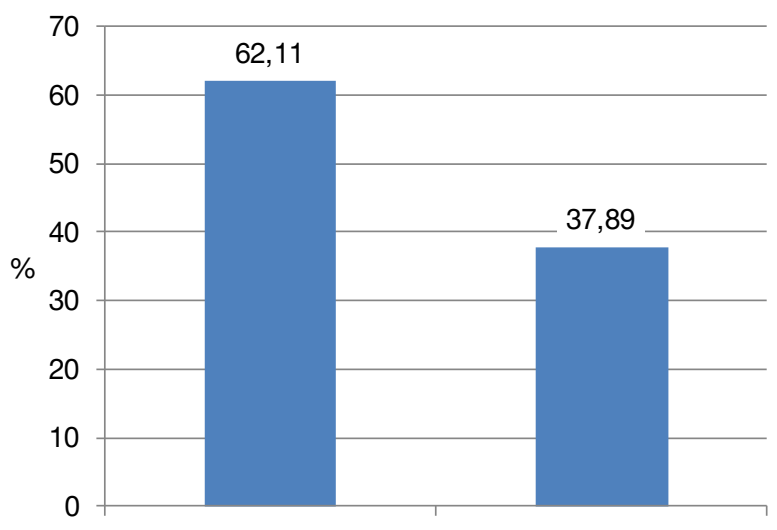

(<4 Disability)

(>4) No disability

IADLS Score

IADLS - Instrumental Activities of Daily Living scale

Figure 2. Frequency distribution of Instrumental Activities of Daily Living scale scores

\section{Associations}

The value of $p=0.000$ for the association of WaLIDD score and VAS showed a positive association; combined, they exert an effect on instrumental activities of daily living. The value of $p=0.003$ for the association of WaLIDD score and IADL indicated an inverse but weak association between dysmenorrhoea and instrumental activities of daily living, with the value of Pearson correlation coefficient $r=-0.231$. The $p$-values, Pearson correlation coefficients $(r)$, and associations among the determined variables are presented in Table 4.

Table 4. Associations among the variables

\begin{tabular}{|l|c|c|}
\hline Variables & $\begin{array}{c}\text { Pearson correlation } \\
\text { coefficient }(r)\end{array}$ & $p$ \\
\hline WaLIDD score and age & -0.004 & 0.955 \\
\hline WaLIDD score and BMI & -0.044 & 0.576 \\
\hline BMI and VAS & -0.139 & 0.079 \\
\hline BMI and IADL & 0.135 & 0.089 \\
\hline WaLIDD score and VAS & 0.597 & $0.000^{*}$ \\
\hline IADL and VAS & -0.437 & $0.000^{*}$ \\
\hline WaLIDD score and IADL & -0.231 & $0.003^{*}$ \\
\hline
\end{tabular}

WaLIDD - working ability, location, intensity, days of pain, dysmenorrhoea, BMI - body mass index, VAS - visual analogue scale, IADL - Instrumental Activities of Daily Living scale * significant at $p<0.05$

WaLIDD - working ability, location, intensity, days of pain, dysmenorrhoea 


\section{Discussion}

Our findings revealed that dysmenorrhoea was present more frequently in students than the staff management or faculty members, as increasing age caused a reduction in the frequency of dysmenorrhoea. The study concludes that females with normal weight $(66.50 \%)$ were more prone to dysmenorrhoea than the underweight, overweight, and obese participants. Out of the 161 participants, the majority (98) had moderate, the minority (51) had severe, and some (12) had mild dysmenorrhoea. The pain intensity as evaluated with VAS turned out severe in $42.90 \%$ of the subjects. The effect of dysmenorrhoea on the instrumental activities of daily living was assessed by Lawton IADL scale; more than half of the participants $(62.11 \%)$ had instrumental activities of daily living disability and $37.89 \%$ presented no disability.

Azagew et al. [25] reported that a minority (29\%) of the investigated students had mild dysmenorrhoea and most of them $(60.8 \%)$ had moderate dysmenorrhoea, while some $(10.2 \%)$ exhibited severe dysmenorrhoea during menstruation. The majority of the participants complained that dysmenorrhoea influenced their educational accomplishment and they were unable to join their class; a minority of the subjects had an impediment in their daily routines and consternation because of dysmenorrhoea.

Al-Asadi and Abdul-Qadir [23] used a partially structured survey form and VAS to assemble information and revealed that $54.3 \%$ of the examined students had moderate, $12.8 \%$ had mild, and $32.9 \%$ had severe dysmenorrhoea. Most participants experienced obstacles in their regular activities, over a half could not focus attention during lectures, some were unable to join their class, while a minority of the students did not accomplish the house projects.

Ibrahim et al. [26] assessed the prevalence and risk factors of dysmenorrhoea and their outcomes. A total of $30.6 \%$ of the participants experienced mild dysmenorrhoea, $30.8 \%$ had moderate, and $38.6 \%$ had severe dysmenorrhoea. As for the effects of dysmenorrhoea, the students reported that they mostly suffered from emotional instability and impediment in their regular activities; a minority of them complained about sleeping disorders, limited concentration, and an impediment of social life.

Mohammed et al. [27] reported that $47.8 \%$ of the investigated students suffered from mild pain, $40 \%$ had moderate pain, and some experienced severe dysmenorrhoea. Because of dysmenorrhoea, more than half of the students did not concentrate on their lectures and were unable to join their class, while a minority had difficulties with accomplishing their homework and participating in sports.

Omorogiuwa and Ekhegbesela [28] determined the influence of $\mathrm{BMI}$ and blood pressure on dysmenorrhoea. In this study, $77.5 \%$ of students suffered from dysmenorrhoea, while a minority had menstruation without dysmenorrhoea. The $Z$-test was used to recognize the association of BMI and blood pressure in the females with and without dysmenorrhoea. There was a significant relationship between BMI values of the students with dysmenorrhoea and those without dysmenorrhoea. No association was observed between the blood pressure values of the participants with and without dysmenorrhoea. The study revealed that increased BMI was a feasible predictor of dysmenorrhoea occurrence.

The weakness of this research is that it was impossible to add references of previous studies to support the research because those other studies contained inadequate information. The strength of this research is that the implementation of its results in the society will be beneficial for the females of the coming generation. It provides awareness to females that during dysmenorrhoea, their lives are disturbed and the symptoms cause impacts on their instrumental activities of daily living.

\section{Limitations}

There are several limitations of this research. It is an observational cross-sectional study, so it lacks the potential to identify the risk factors of dysmenorrhoea. An educational institution in Gujrat was included so a similar study could be performed on a larger scale involving different locations and wider age groups. It should be also conducted among married women.

\section{Conclusions}

Our study demonstrates that the majority of the participants had moderate dysmenorrhoea and that the phenomenon is more frequent in normal weight women than in those who are underweight, overweight, or obese. Nearly half of the females presented severe intensity of pain and more than a half experienced instrumental activities of daily living disability. The study reports statistically significant associations between dysmenorrhoea and instrumental activities of daily living $(p=0.003)$.

\section{Acknowledgements}

The authors would like to thank all individuals who contributed to the completion of this work, especially the study participants.

\section{Disclosure statement}

No author has any financial interest or received any financial benefit from this research.

\section{Conflict of interest}

The authors state no conflict of interest.

\section{References}

1. Pejčić A, Janković S. Risk factors for dysmenorrhea among young adult female university students. Ann Ist Super Sanita. 2016;52(1):98-103; doi: 10.4415/ANN_ 16_01_16.

2. Orhan C, Çelenay ŞT, Demirtürk F, Özgül S, Üzelpasacı E, Akbayrak T. Effects of menstrual pain on the academic performance and participation in sports and social activities in Turkish university students with primary dysmenorrhea: a case control study. J Obstet Gynaecol Res. 2018;44(11):2101-2109; doi: 10.1111/jog.13768.

3. Giletew A, Bekele W. Prevalence and associated factors of primary dysmenorrhea among Debre Tabor University students, North Central Ethiopia. Int J Biomed Eng Clin Sci. 2018;4(4):70-74; doi: 10.11648/j.jbecs.20180404.11.

4. Seven M, Güvenç G, Akyüz A, Eski F. Evaluating dysmenorrhea in a sample of Turkish nursing students. Pain Manag Nurs. 2014;15(3):664-671; doi: 10.1016/j.pmn. 2013.07.006.

5. Aziato L, Dedey F, Clegg-Lamptey JNA. The experience of dysmenorrhoea among Ghanaian senior high and university students: pain characteristics and effects. Reprod Health. 2014;11:58; doi: 10.1186/1742-4755-11-58.

6. Kaur S, Sheoran P, Sarin J. Assessment and comparison of dysmenorrhea in terms of severity of pain and utilization of non steroid anti-inflammatory drugs among unmarried and married women. In J Caring Sci. 2015;8(3): 737-746. 
7. Akinnubi CF. Influence of dysmenorrhea and menorrhagia on academic performance among female students in tertiary institutions in Ondo State Nigeria. World J Soc Sci. 2016;3(2):34-41; doi: 10.5430/wjss.v3n2p34.

8. Okoro RN, Malgwi H, Okoro GO. Evaluation of factors that increase the severity of dysmenorrhoea among university female students in Maiduguri, North Eastern Nigeria. Internet J Allied Health Sci Pract. 2013;11(4):7; doi: 10.46743/1540-580X/2013.1458.

9. Rajalaxmi V, Paul J, Vijayapriya V, Gracy RH, Kamatchi K. Prevalence of dysmenorrhea among school \& college girls and postpartum women. Drug Invent Today. 2018;10(5): 769-772.

10. Potur DC, Bilgin NC, Komurcu N. Prevalence of dysmenorrhea in university students in Turkey: effect on daily activities and evaluation of different pain management methods. Pain Manag Nurs. 2014;15(4):768-777; doi: 10.1016/j.pmn.2013.07.012.

11. Yesuf TA, Eshete NA, Sisay EA. Dysmenorrhea among university health science students, Northern Ethiopia: impact and associated factors. Int J Reprod Med. 2018; 2018:9730328; doi: 10.1155/2018/9730328.

12. Aktaş $D$. Prevalence and factors affecting dysmenorrhea in female university students: effect on general comfort level. Pain Manag Nurs. 2015;16(4):534-543; doi: 10.1016/ j.pmn.2014.10.004.

13. Kural M, Noor NN, Pandit D, Joshi T, Patil A. Menstrual characteristics and prevalence of dysmenorrhea in college going girls. J Family Med Prim Care. 2015;4(3):426431; doi: 10.4103/2249-4863.161345.

14. Helwa HAA, Mitaeb AA, Al-Hamshri S, Sweileh WM. Prevalence of dysmenorrhea and predictors of its pain intensity among Palestinian female university students. BMC Womens Health. 2018;18(1):18; doi: 10.1186/ s12905-018-0516-1.

15. De Sanctis V, Soliman A, Bernasconi S, Bianchin L, Bona G, Bozzola M, et al. Definition and self-reported pain intensity in adolescents with dysmenorrhea: a debate report. Riv Ital Med Adolesc. 2016;14(2):5-11.

16. Pitangui ACR, de A Gomes MR, Souza Lima A, Schwingel PA, dos S Albuquerque AP, de Araújo RC. Menstruation disturbances: prevalence, characteristics, and effects on the activities of daily living among adolescent girls from Brazil. J Pediatr Adolesc Gynecol. 2013;26(3):148152; doi: 10.1016/j.jpag.2012.12.001.

17. Yasir S, Kant B, Dar MF. Frequency of dysmenorrhoea, its impact and management strategies adopted by medical students. J Ayub Med Coll Abbottabad. 2014;26(3): 349-352.

18. Rawat N, Thakur A, Sharma S, Prashad J, Kaur S, Ghai S, et al. Prevalence of dysmenorrhoea, and its impact on activities of daily living (ADLS) among nursing personnel. Baba Farid Univ Nurs J. 2016;10(1):30-38.

19. Hailemeskel S, Demissie A, Assefa N. Primary dysmenorrhea magnitude, associated risk factors, and its effect on academic performance: evidence from female university students in Ethiopia. Int J Womens Health. 2016; 8:489-496; doi: 10.2147/IJWH.S112768.

20. Kizilirmak A, Kartal B, Calpbinici P. Prevalence of dysmenorrhea in young women and their coping methods. Med Sci Int Med J. 2019;8(2):291-295; doi: 10.5455/ medscience.2018.07.8937.

21. Stineman MG, Xie D, Pan Q, Kurichi JE, Saliba D, Schüssler-Fiorenza Rose SM, et al. Understanding non-performance reports for instrumental activity of daily living items in population analyses: a cross sectional study.
BMC Geriatr. 2016;16(1):64; doi: 10.1186/s12877-0160235-0.

22. Hopkins RO, Suchyta MR, Kamdar BB, Darowski E, Jackson JC, Needham DM. Instrumental activities of daily living after critical illness: a systematic review. Ann Am Thorac Soc. 2017;14(8):1332-1343; doi: 10.1513/Annals ATS.201701-059SR.

23. Al-Asadi JN, Abdul-Qadir RA. Dysmenorrhea and its impact on daily activities among secondary school students in Basra, Iraq. J Fac Med Baghdad. 2013;55(4):339344; doi: 10.32007/jfacmedbagdad.554576.

24. Jenabi E, Fereidooni B, Karami M, Masoumi SZ, Safari M, Khazaei S. The effect of bee prepolis on primary dysmenorrhea: a randomized clinical trial. Obstet Gynecol Sci. 2019;62(5):352-356; doi: 10.5468/ogs.2019.62.5.352.

25. Azagew AW, Kassie DG, Walle TA. Prevalence of primary dysmenorrhea, its intensity, impact and associated factors among female students' at Gondar town preparatory school, Northwest Ethiopia. BMC Womens Health. 2020;20(1):5; doi: 10.1186/s12905-019-0873-4.

26. Ibrahim NK, AIGhamdi MS, Al-Shaibani AN, AIAmri FA, Alharbi HA, Al-Jadani AK, et al. Dysmenorrhea among female medical students in King Abdulaziz University: prevalence, predictors and outcome. Pak J Med Sci. 2015;31(6):1312-1317; doi: 10.12669/pjms.316.8752.

27. Mohammed H, Hassen N, Musa A. Dysmenorrhea and associated factors among secondary school students in East Hararghe zone, Eastern Ethiopia. East Afr J Health Biomed Sci. 2019;3(1):39-48.

28. Omorogiuwa A, Ekhegbesela OA. Dysmenorrhea: relationship to body mass index (BMI) and blood pressure. Nigerian Soc Exp Biol J. 2014;14(1):43-45. 